\title{
Avanços na Política de Saúde Bucal em Portugal.
}

\section{Advances in Portuguese Oral Health Policy.}

\section{Avances en la Política de Salud Bucal portuguesa.}

Alexandre Morais Nunes ${ }^{1}$

Manuel Lourenço Nunes ${ }^{2}$

\begin{abstract}
RESUMO: A aposta na saúde bucal, apesar de não ser devidamente valorizada por muitos Governos, é importante para o desenvolvimento da população já que a patologia oral pode ter efeitos nefastos nos mais diversos sistemas orgânicos que asseguram a sobrevivência dos pacientes. Em Portugal, a promoção da saúde bucal nunca foi uma prioridade para os sucessivos Governos. Apenas no ano de 2005 se implementou, no âmbito do Plano Nacional de Saúde, o Programa Nacional de Promoção da Saúde Oral (PNSO), que dez anos mais tarde, em 2015, sofreu novas alterações. O presente artigo realiza uma revisão teórica do desenvolvimento da promoção da saúde oral em Portugal, retratando toda a história da sua criação, evolução e perspectivas futuras e cobertura, desde o início do Programa até ao projeto de integração da Saúde Oral no âmbito da atenção primária à saúde.
\end{abstract}

Palavras-chave: Promoção da saúde, Saúde bucal, Programas Nacionais de Saúde

\begin{abstract}
The focus on oral health, not valued by many governments, is important for the development of the population, because the oral pathology can have harmful effects on the most diverse organ systems, that ensure patient survival. In Portugal, the promotion of oral health has never been a priority for successive Governments. In 2005, the National Program for the Promotion of Oral Health (PNSO) was implemented under the National Health Plan. Ten years later, in 2015, it underwent new changes. This article presents a theoretical review of the development of oral health promotion in Portugal, describing the whole history of its creation, evolution and future perspectives and coverage, from the beginning of the Program to the integration project of Oral Health in primary health care the health.
\end{abstract}

Keywords: Health promotion, Oral health, National Health Programs.

RESUMEN: La apuesta a la salud bucal, a pesar de no ser debidamente valorada por muchos

1 Centro de Administração e Políticas Públicas, ISCSP, Lisboa. Professor Auxiliar Convidado, Políticas de Saúde.

2 Professor Associado Convidado da Universidade da Beira Interior. Portugal

ISSN 1982-8829 Tempus, actas de saúde colet, Brasília, 11(4), 25-39, dez, 2017. Epub Ago/2018 
Gobiernos, es importante para el desarrollo de la población ya que la patología oral puede tener efectos nefastos en los más diversos sistemas orgánicos que aseguran la supervivencia de los pacientes. En Portugal, la promoción de la salud bucal nunca fue una prioridad para los sucesivos gobiernos. Sólo en el año 2005 se implementó, en el marco del Plan Nacional de Salud, el Programa Nacional de Promoción de la Salud Oral (PNSO), que diez años más tarde, en 2015, sufrió nuevas alteraciones. El presente artículo realiza una revisión teórica del desarrollo de la promoción de la salud oral en Portugal, retratando toda la historia de su creación, evolución y perspectivas futuras y cobertura, desde el inicio del Programa hasta el proyecto de integración de la Salud Oral en el ámbito de la atención primaria la salud.

Palabras clave: Promoción de la salud, Salud bucal, Programas Nacionales de Salud.

\section{INTRODUÇÃO}

A saúde é um direito fundamental que se encontra inscrito na Declaração Universal dos Direitos Humanos, publicada pela Organização Mundial de Saúde (OMS) em $1948^{1}$.

Asaúde é vista pelos cidadãos como um estado de bem-estar que lhes permite um bom desempenho a nível físico, psicológico e social ${ }^{2,3}$ e surge no topo da lista das principais preocupações expressas pelos portugueses quando respondem a inquéritos sobre o que consideram importante ${ }^{4}$.

A constituição da República Portuguesa consagrou em 1974 estes princípios, considerando que todos têm direito à proteção da saúde e o dever de a defender e promover ${ }^{5}$. Este direito à proteção da saúde foi consagrado, cinco anos mais tarde, com a criação de um Serviço Nacional de Saúde (SNS), universal, geral e gratuito, pela criação de condições econômicas, sociais e culturais que garantam a proteção da infância, da juventude e da velhice e pela melhoria das condições de vida, pela promoção da cultura física e desportiva, escolar e popular e ainda pelo desenvolvimento da educação sanitária do povo ${ }^{6}$.

Os atos legislados no âmbito da proteção da saúde exigiram ao Estado um reforço do seu papel com o objetivo de garantir o acesso aos cidadãos, independentemente da condição econômica, no âmbito da medicina preventiva, curativa e reabilitação. Assim, se procedeu a uma distribuição equitativa de unidades de saúde por todo o país, à regulação do setor da saúde (público e privado) e ainda controlar a produção e comercialização de produtos farmacêuticos (químicos ou biológicos) ${ }^{6}$.

Porém, a relação que se estabelece da promoção da saúde não é unilateral. A promoção da saúde também é devida a cada um dos elementos da sociedade, tanto a nível individual como coletivo. Neste contexto, o cidadão assume uma enorme importância no funcionamento dos serviços de saúde ${ }^{7,8}$. Assim, a proteção da saúde não é apenas um direito social, mas também um dever individual, e que a sociedade deve organizar-se de modo a promover a saúde dos cidadãos.

Atualmente a construção de um Serviço Nacional de Saúde é percebida como uma conquista 
da população portuguesa, que se tem mantido até aos dias de hoje e que responde às necessidades de todos os cidadãos ${ }^{9}$.

Nas prestações do SNS, a saúde oral ficou sempre fragilizada. Os médicos dentistas não foram integrados, em número adequado, nem na carreira adequada, para fazer face às necessidades da população portuguesa, cuja prevalência da patologia oral era elevada, na população com dificuldade econômica e com baixa literacia.

Apesar de alguns médicos dentistas estarem integrados nas unidades do SNS, a verdade é que a prestação de cuidados de saúde oral era até 2005 uma atividade predominantemente desenvolvida no setor privado. Dessa forma, só poderia aceder quem tivesse capacidade econômica, podendo ficar sem acesso os grupos de risco como grávidas, crianças e idosos. Estas situações em particular foram parcialmente resolvidas. Para colmatar esta situação foi desenvolvido um Programa Nacional de Promoção da Saúde Oral, que desenhou uma estratégia global de intervenção assente na promoção da saúde, prevenção e tratamento das doenças bucais e que se desenvolve ao longo do ciclo de vida ${ }^{10}$.

O Programa Nacional de Promoção de Saúde Oral é um instrumento da política de saúde que tem contribuído para a melhoria da qualidade e para a promoção de hábitos de vida saudáveis, prevenção da patologia oral, com uma ação próxima das escolas, e de um conjunto de grupos alvo (através do programa cheque-dentista). Em 2016, são beneficiários deste programa as crianças e jovens com menos de 18 anos, as grávidas seguidas nos Centros de Saúde do SNS, os idosos que beneficiam do complemento solidário e os cidadãos infetados com o vírus do HIV/AIDS.

O Programa Nacional de Promoção de Saúde Oral (PNPSO), em Portugal, é uma ferramenta essencial da política de saúde, que contribui para a melhoria da qualidade e eficácia da prestação dos cuidados de saúde oral e que proporciona um conjunto de estratégias integradas.

Este artigo descreve a estratégia de promoção da saúde oral desenvolvida em Portugal, contando toda a história da sua criação, evolução, fases e perspectivas futuras e encontra-se sistematizado em quatro seções: a primeira apresenta os principais problemas/necessidades em saúde oral; a segunda sistematiza o nascimento do Programa Nacional de Promoção da Saúde Oral; a terceira desenvolve as fases de alargamento do projeto, para proporcionar o acesso a cuidados de saúde em todo o ciclo de vida e no capítulo final é apresentada uma nova perspectiva para a saúde oral que passa pela sua integração nas atividades da atenção primária à saúde.

Além da narração dos processo histórico, apresentação e análise das medidas tomadas é apresentada a discussão sobre o futuro da prestação. Foram analisadas documentos da DireçãoGeral da Saúde, publicações legais e consultados peritos na área através dos seus escritos.

No final, verificamos que o Programa Nacional de Promoção da Saúde Oral contribuiu para a melhoria dos cuidados de saúde da população, sendo uma obra ainda em aberto. Segundo dados 
publicados no Portal oficial do Ministério da Saúde ${ }^{11}$, no ano 2008 o Programa abrangia um total de 821.526 tratamentos e em 2016 esse número alcançou aos 1,6 milhões de tratamentos. No entanto, consideramos também que o processo de internalização desta atividade na atenção primária tardou por chegar, pois o modelo de cheque dentista demonstrou-se dispendioso e pouco regulado. São igualmente feitas breves sugestões/recomendações futuras.

\section{Principais afeções/patologias no âmbito da saúde oral}

As doenças bucais, como a cárie dentária e as doenças periodontais continuam a ser um problema importante de saúde pública, que afetam grande parte da população, e condicionam o estado geral de saúde, de bem-estar e a qualidade de vida. Em países desenvolvidos as despesas com o tratamento de doenças bucais igualam ou ultrapassam os custos de outras doenças, como o câncer (podendo este manifestar-se também nas estruturas orais), a diabetes e as patologias cardiovasculares $^{12}$.

A patologia bucal tem reflexo direto nos encargos sociais e familiares. Por um lado, ao se limitar o trabalho e condicionar a produtividade em larga escala, a patologia bucal poderá estagnar, irremediavelmente, o desenvolvimento econômico. Sem saúde não há produção de riqueza, não há possibilidade de progresso. Por outro lado, há a consciência coletiva de que estas patologias são vulneráveis a estratégias de intervenção conhecidas e comprovadamente eficientes - uma das condições para serem classificadas como doenças de saúde pública. Esta prevenção seria menos onerosa, segundo numerosos estudos efetuados, que o tratamento das patologias atrás referidas ${ }^{13}$.

No entanto, em Portugal, os problemas dentários não estão quantificados, pelo menos para uma grande faixa da população. Os dados sobre o estado da saúde oral da população não estão atualizados. Tal como em qualquer outro campo da medicina, são necessários alguns estudos epidemiológicos para que se possa, após o diagnóstico da situação, planejar e agir com a eficácia desejada ${ }^{14}$.

Genericamente, quando se fala em doenças orais, há a tendência de pensar apenas em patologia dentária e nas consequências imediatas que daí podem resultar: cárie dentária, gengivite, abcesso, dor. Remetendo para segundo plano as doenças sistémicas com repercussões orais, de que são exemplos as doenças inflamatórias crónicas intestinais ${ }^{14,15,16}$, a diabetes ${ }^{17}$ e a leucemia ${ }^{18}$, entre várias outras. É importante pensar nas implicações locais da patologia bucal e das suas consequências no organismo.

Uma cárie dentária poderá causar dor local, seja pelo desenvolvimento de uma pulpite crônica, seja pela evolução até à necrose séptica, com formação de abcesso. O abcesso poderá tornar-se crônico ou evoluir para uma celulite que, em última instância, poderá colocar em perigo a vida do doente ${ }^{19}$. Nas situações referidas, um estudante não consegue, devido à dor, participar nas aulas, nem tão pouco estudar; um adulto trabalhador não conseguirá desempenhar as suas funções 
profissionais. Há necessidade de consultar o profissional de saúde, adquirir medicamentos e, se necessário, ficar internado em ambiente hospitalar. Verifica-se, assim, o absenteísmo escolar ou o absentismo laboral, com a consequente não produção e com os gastos financeiros que a situação acarreta para a pessoa e para a sociedade. Ainda a nível local, uma simples pericoronarite incapacita o doente para utilizar a cavidade oral, naquelas que deveriam ser as suas funções fisiológicas e, quando não tratada, pode evoluir de imediato, e provocar à distância, outras patologias mais graves a nível respiratório e cerebral, por exemplo ${ }^{20}$.

A nível sistémico, os problemas da cavidade oral poderão, à distância, provocar alterações que podem ir de uma simples pelada na cabeça até uma sépsis ${ }^{21}$, causadora da morte de um paciente $^{22}$. De permeio, as lesões valvulares cardíacas, as glomerulonefrites pós-estreptocócicas, o reumatismo articular agudo. Numa grávida, os problemas bucais, especialmente as cáries dentárias e as periodontopatias poderão contribuir para o baixo peso à nascença, da criança em crescimento e maturação uterina ${ }^{22}$.

\section{A criação do Programa Nacional para a Promoção da Saúde Oral}

Nos anos 80, a opção política para os cuidados de saúde não contemplados no SNS inclui a celebração de convenções e acordos com prestadores privados, o que não se verificou com a saúde oral $^{23}$. Estes cuidados eram prestados pelo setor privado e pagos diretamente pelos clientes. Esta foi uma grande lacuna do SNS, cujos efeitos se tentaram minimizar em 1985 com a promoção da saúde oral através de programas escolares (higiene oral, educação alimentar e administração de flúor).

Catorze anos mais tarde, em 1999, o programa foirevisto com oacionamento da complementaridade público-privado, ou seja, o SNS por meio da atenção primária passou a encaminhar as crianças com necessidades de tratamento de saúde bucal para o sector privado, sendo responsável pelo pagamento. A essa data, o programa passou a ser conhecido como "Programa de Promoção da Saúde Oral em Crianças e Adolescentes" (PPSOCA). Um ano antes tinha sido criado o PAMDIA - Programa de Assistência Médico Dentária para a Infância e Adolescência, que limitava a uns breves milhares de jovens, entre um universo de milhões, a beneficiar do programa de prevenção e tratamentos no âmbito da Saúde Oral - mais propriamente, no âmbito dentário.

Em 2005 foi manifestada uma preocupação do Governo com a elevada prevalência da patologia oral na população infantil e juvenil e decidiu-se apostar na prevenção da cárie e das doenças periodontais, o que gerava uma redução de custos econômicos e proporcionaria ganhos significativos em saúde. Assim foi criado o Programa Nacional de Promoção da Saúde Oral (PNPSO) ${ }^{10}$.

O PNPSO foi integrado no Plano Nacional de Saúde e tinha como principais objetivos:

- Reduzir a incidência e a prevalência das doenças orais nas crianças e adolescentes;

- Melhorar conhecimentos e comportamentos sobre saúde oral;

ISSN 1982-8829 Tempus, actas de saúde colet, Brasília, 11(4), 25-39, dez, 2017. Epub Ago/2018 
- Promover a equidade na prestação de cuidados de saúde oral às crianças e jovens com Necessidades de Saúde Especiais.

A atividade realizada no âmbito deste programa deveria ser desenvolvida prioritariamente no setor público através dos profissionais dos centros de saúde e dos serviços de estomatologia hospitalar por meio de ações dirigidas à comunidade escolar e às famílias. Quando não fosse possível, seria possível recorrer ao setor privado que poderiam prestar cuidados de medicina dentária através da contratualização para os atos não satisfeitos no $\mathrm{SNS}^{24}$.

O programa implementado no ano de 2005 era concebido para crianças desde o nascimento até aos 16 anos e apresentava como estratégias de intervenção a promoção da saúde oral no contexto familiar e escolar, a prevenção das doenças orais e o diagnóstico precoce e tratamento dentário para atingir os objetivos de melhorar os comportamentos alimentares, melhorar o conhecimento da higiene oral, reduzir a incidência e prevalência da cárie dentária, aumentar a percentagem de crianças livres de cárie e prestar um cuidado especial a crianças e jovens com necessidades especiais e pertencentes a grupos economicamente desfavorecidos ou socialmente excluídos ${ }^{24}$.

Na prática, em 2005, o Programa Nacional de Promoção da Saúde Oral (PNPSO) deu um passo importante na promoção da saúde oral, mas a estratégia focou-se muito nas orientações de utilização de fluoretos.

No PNPSO embora o encaminhamento seja realizado pelo médico de familia existe um maior controle pois o cheque está condicionado ao tipo de tratamento e permite ter um maior monitoramento sobre os tratamentos já realizados que, obrigatoriamente, são registrados numa plataforma nacional controlada pelos serviços locais, regionais e centrais, a níveis diferentes. Estes registos dos tratamentos só poderão efetuar-se se houver um registo anterior do diagnóstico e de um plano de tratamento. Enquanto, no anterior (PPSOCA), a porta de entrada da criança iniciavase com uma equipa de Saúde Escolar onde, eventualmente, poderia haver algum profissional de saúde oral. Essa equipa referenciava as crianças, se os pais e os professores estivessem de acordo em que beneficiassem do Programa. Depois, os pacientes eram distribuidos por consultórios privados com médicos dentistas. O Estado pagava por criança tratada com um controlo deficitário e sem avaliação.

\section{Fases do Programa Nacional para a Promoção da Saúde Oral}

O PNPSO, entre 2005 e 2008, proporcionou o acesso a cuidados curativos a 60.000 crianças e jovens. No entanto, o Ministério da Saúde considerou este número desajustado e reforçou a necessidade de assegurar a prestação equitativa de cuidados ao longo do ciclo de vida e na satisfação dos grupos mais vulneráveis. Com base nestes objetivos o PNPSO foi sujeito a várias alterações que culminaram com o alargamento da cobertura/população alvo, que se estenderam até ao ano 2015. 


\subsection{Alargamento do PNPSO a grávidas e idosos (2008)}

Em 2008, o executivo decidiu iniciar o alargamento pela inclusão de mulheres grávidas seguidas no SNS e idosos beneficiários do complemento solidário e acompanhados no SNS, com o objetivo de avaliar e diminuir a incidência e a prevalência das doenças orais nestes dois grupos, através da prestação de um conjunto de cuidados de medicina dentária, nas áreas de prevenção, diagnóstico e tratamento $^{25}$.

A opção pelas mulheres grávidas teve em conta:

- As mudanças hormonais que aumentam a probabilidade de aparecimento de doenças periodontais que afetam a boa higiene oral e como consequência pode dar causar o desenvolvimento de cárie dentária;

- $\quad$ A associação entre o nível de doença oral e a prematuridade, baixo peso ao nascer e pré-eclâmpsia (até mesmo ocorrer pode ocorrer a transmissão de bactérias envolvidas na génese da doença oral para os filhos).

Em relação aos idosos, a opção surgiu pelo facto da doença oral (periondonpatias e perda de peças dentárias) estar associada ao envelhecimento e aos baixos rendimentos. Foi estabelecido que o acesso a consultas de medicina dentária seria realizado através da emissão de um chequedentista (no valor de $40 €$ ), personalizado, emitido e entregue pelo centro de saúde onde o utente é seguido. Estes cheques cobrem os tratamentos necessários, de modo a garantir que a grávida, no final do tratamento, fique livre de lesões ativas de cárie dentária. No caso dos idosos darão acesso a um conjunto de cuidados de saúde oral essenciais para preparar a eventual aplicação de próteses dentárias, bem como para identificar e tratar outros problemas de saúde oral neste grupo etário.

Tabela 1 - Condicionantes da emissão do cheque-dentista

\begin{tabular}{|l|l|l|}
\hline & \multicolumn{1}{|c|}{ Grávidas } & \multicolumn{1}{c|}{ Idosos } \\
\hline Documentos a apresentar & $\begin{array}{l}\text { Atestado de gravidez } \\
\text { Identificação do número de beneficiário }\end{array}$ & $\begin{array}{l}\text { Identificação do número de } \\
\text { beneficiário }\end{array}$ \\
\hline Número máximo de cheques & 3 Durante a gravidez (120€) & 2 Cheques por ano $(80 €)$ \\
\hline Prestadores & $\begin{array}{l}\text { Podem escolher qualquer prestador privado } \\
\text { que conste na lista de médicos aderentes. }\end{array}$ & \\
\hline
\end{tabular}

Fonte: Despacho n. ${ }^{o} 4324 / 2008$, de 22 de janeiro ${ }^{24}$

Embora tenha ocorrido a implementação do cheque dentista em grávidas e idosos,as atividades de promoção da saúde oral destinadas a crianças e jovens escolarizados até aos 16 anos de idade mentiveram o modelo de funcionamento definido inicialmente no $\mathrm{PNPSO}^{26}$. 


\subsection{Alargamento do PNPSO, através de cheque dentista, a crianças e jovens de 7,10 e 13 anos de idade (2009)}

No final de 2008, procedeu-se a uma revisão e reestruturação do Programa Nacional de Promoção de Saúde Oral que tinha por base a simplificação dos processos e o aumento da cobertura da resposta. A esta data foi colocado um fim aos concursos públicos anuais e dos procedimentos altamente burocratizados na contratualização de prestadores privados, que demoravam vários meses a ser aprovados, pois dependiam não apenas do Ministério da Saúde mas do Ministério das Finanças que os tinha de incluir no orçamento e mobilizar as verbas necessárias. Por isso, as consultas realizadas pelo parceiro privado entre março/abril eram pagas só no mês de novembro, ultrapassando o prazo acordado de 30 dias. Dados estes contras, optou-se pelo modelo do cheque-dentista ${ }^{27}$.

A partir de março de 2009, a cobertura do programa através da emissão do cheque dentista é assim alargada a crianças e jovens com idade inferior a 16 anos. Dessa forma, ficam beneficiários da emissão de um cheque dentista as grávidas, os idosos beneficiários do complemento solidário e as crianças e jovens ${ }^{28}$.

Numa primeira fase deste alargamento da emissão de cheques teve-se em consideração que a vulnerabilidade à cárie dentária é muito maior logo após a erupção, o impacto das intervenções suscetíveis de tornarem os dentes mais resistentes será tanto maior, quanto mais precocemente elas se concretizarem. Por isso, tendo em conta a cronologia da erupção dentária, deverão ser intervencionadas prioritariamente as seguintes coortes:

- 7 Anos, na condição de já se ter verificado a erupção dos primeiros molares - dois cheques/ano;

- 10 Anos, na condição de já se ter verificado a erupção dos pré-molares - dois cheques/ano;

- 13 Anos, na condição de já se ter verificado a erupção dos segundos molares - três cheques/ano ${ }^{27}$.

3.3. Alargamento do PNPSO, através de cheque dentista, a crianças e jovens de 8,11 e 14 anos de idade (2010)

No ano seguinte, em 2010, este processo foi alargado a crianças e jovens de 8, 11 e 14 anos de idade, nas situações de dentes permanentes cariados, que tiveram acesso ao Programa de Saúde Escolar no ano anterior e que terminaram os planos do tratamento. A estes jovens foi emitido um cheque-dentista (Cheque Saúde Oral Crianças e Jovens de Idades Intermédias) que dá acesso ao tratamento de dois dentes com cárie ${ }^{29}$. 
É usual a prevalência de problemas orais como as infecções oportunistas, a periodontite e a perda de peças dentárias nos doentes infetados com AIDS $^{30,31}$. Por isso, em 2010 foi considerada a necessidade de abranger, no PNPSO, este grupo de cidadãos ${ }^{32}$.

Para atingir os objetivos propostos, foi estipulado que, no máximo, a cada utente seriam atribuídos seis cheques, distribuídos por duas fases e com uma validade de 12 meses após emissão. A totalidade dos cheques permitiriam o tratamento mínimo de 11 dentes ou 9 nas situações em que o plano do tratamento inclua endodontias ${ }^{33}$.

No caso dos doentes portadores de AIDS, na utilização do primeiro cheque, o estomatologista ou médico dentista deve registar a avaliação oral do doente e elaborar um plano de tratamento de acordo com os cheques disponíveis. Após o terceiro cheque, o médico dentista deve contatar o médico de família (médico dos serviços de atenção primária) solicitando a continuação do processo $^{33}$.

No tratamento de doentes com AIDS deve existir um especial cuidado na garantia da confidencialidade dos dados ${ }^{33}$.

\subsection{Alargamento do PNPSO, através de cheque dentista, a crianças do coorte dos 15 anos completos (2013)}

Programa Nacional de Promoção da Saúde Oral - Crianças e Jovens da rede pública e IPSS da coorte dos 15 anos completos que aos 13 anos de idade utilizaram cheque-dentista ou documento de encaminhamento para a higiene oral ${ }^{34,35}$. Para esses casos, o cheque poderá ser utilizado entre 1 de janeiro e 31 de outubro do ano em que foi emitido e tem por objetivo o tratamento de todas as cáries ativas em dentes permanentes e a aplicação de selantes de fissuras em todos os molares e pré-molares saudáveis ${ }^{35}$.

\subsection{Alargamento do PNPSO à intervenção precoce no câncer oral (2014)}

A taxa de incidência de câncer de boca em Portugal cresceu na última década e apresentou baixa sobrevivência. Este facto levou a que houvesse uma preocupação especial na prevenção de casos através do diagnóstico precoce. Assim, em março de 2014 procedeu-se a inclusão desta atividade no âmbito do PNPSO com atribuição de cheque dentista ${ }^{36}$.

A implementação deste rastreio ganha uma importância no seguimento de uma estratégia consolidada no âmbito do PNPSO, já que alguns dos novos adultos foram crianças abrangidas pelo programa em toda a fase da vida, o que reflete a continuidade da promoção da saúde oral.

A iniciativa de rastreio de câncer oral parte do médico de família através de um rastreio oportunista com pacientes de elevado risco (cheque diagnóstico no valor de $15 €$ ) ou por diagnóstico de lesões malignas ou potencialmente malignas, detectadas no seguimento de queixa do doente. Neste caso, 
deve ser complementarmente realizada uma biopsia, sendo para isso emitido um cheque-biópsia (valor de 50€) para um médico aderente habilitado. No seguimento do processo em caso de tumor maligno o doente é encaminhado para o Instituto Português de Oncologia da respetiva área de residência ${ }^{36}$.

\subsection{Alargamento do PNPSO aos jovens (até 18 anos), crianças com n e c e s s i d a d e s especiais e pacientes portadores de AIDS (2015)}

Em 2015 verificaram-se algumas lacunas no Programa Nacional de Promoção da Saúde Oral. O alargamento efetuado pretendeu corrigi-las, reforçando a eficácia do programa implementado.

Foi alargada a cobertura para os jovens de 18 anos que tinham sido beneficiários do PNPSO e concluídos os tratamentos até aos 16 anos. Ainda no âmbito das crianças e jovens, verificou-se que aqueles que era portadores de necessidades especiais nem sempre beneficiavam do programa e como tal foi reforçada a cobertura nas idades de 7, 10 e 13 anos, nomeadamente para os casos de doença mental, paralisia cerebral, trissomia 21 que não tenham sido abrangidos pelo programa e na sequência de triagem realizada pelo SNS. Nesses casos, sempre que fosse expectável a eventual necessidade de recorrer a sedação do paciente, o médico de família encaminhava o caso para os cuidados especializados, nomeadamente para os serviços de estomatologia existente nos hospitais públicos ${ }^{36}$.

O risco de problemas de saúde oral acresce em pacientes portadores de VIH/AIDS, de tal forma que os seis cheques se consideraram insuficientes. Passou a ser possível a emissão de ciclos adicionais (até dois cheques dentista) de acordo com as necessidades especiais para os doentes que já tinham sido abrangidos pelo programa e que não faziam tratamentos há mais de 24 meses ${ }^{37}$.

\section{A internalização da saúde oral na atenção primária}

A extensão a 2020 do Plano Nacional de Saúde português define como prioritária a melhoria da equidade e do acesso aos cuidados de saúde, com especial atenção às pessoas mais vulneráveis. É com base neste eixo que o atual Governo de Portugal promoveu a expansão da rede de atenção primária com a ampliação da cobertura do SNS na área da Saúde Oral ${ }^{38}$.

O Ministério da Saúde para o período de governação entre 2016-2019, no âmbito do Programa Nacional de Saúde Oral, efetuou em 2016 uma revisão do PNPSO no sentido de integrar a prestação de cuidados de saúde oral no âmbito dos Centros de Saúde, promovendo a articulação entre os vários profissionais entre a atenção primária e a hospitalar, numa visão integrada e universal (médicos dentistas, médicos de saúde pública, médicos de medicina geral e familiar, enfermeiros de família, higienistas orais, nutricionistas, psicólogos, entre outros profissionais de saúde, bem como com os serviços de estomatologia e outras especialidades hospitalares) ${ }^{39}$. O objetivo não foi acabar ou reduzir no imediato o cheque dentista, mas sim alargar a cobertura para outros casos que não os previstos no PNPSO, diminuindo progressivamente o vinculo com o setor privado. 
A promoção da saúde e a prevenção da doença oral está aliada a uma política ativa que desde setembro de 2016 conta, para além do cheque-dentista, com a prestação de cuidados de saúde oral no SNS. Está a ser testado o processo de implementação da saúde oral na atenção primária, através de uma experiência piloto que visa um aproveitamento dos recursos físicos existentes no SNS (instalações e dos equipamentos) e a contratação de profissionais necessários a essa prestação ${ }^{39}$. Estas experiências piloto decorrem de forma faseada:

- $\quad$ Primeira etapa: de setembro a dezembro de 2016. Têm acesso a consultas de saúde oral na atenção primária, os doentes portadores de neoplasia, diabetes, insuficiência renal em hemodiálise ou diálise peritoneal ou transplantados, patologia cardíaca, patologia respiratória crónica, desde que inscritos nos Agrupamentos de Centros de Saúde onde se realizam as experiências, tendo ainda prioridade dentro de cada patologia, os doentes com mais dificuldades econômicas;

- $\quad$ Já se realizou em 2017, o alargamento da prestação de saúde oral a todos os utentes inscritos nos ACES onde ocorrem as experiências piloto, de forma pregressa e mediante a encaminhamento do médico de família;

- $\quad$ Até final de 2018 esta medida será implementada de forma gradual e sucessiva em todo o país.

Estas experiências piloto foram desenvolvidas nas Administrações Regionais de Saúde do Alentejo e de Lisboa e Vale do Tejo. A tabela seguinte apresenta os locais onde estão a ser desenvolvidas.

Tabela 2 - Unidades alvo do projeto-piloto

\begin{tabular}{|c|c|c|}
\hline & ACES & Centro de Saúde \\
\hline ARS Alentejo & ACES Alentejo Central & $\begin{array}{l}\text { Centro de Saúde de Montemor-o-Novo; } \\
\text { Centro de Saúde de Portel. }\end{array}$ \\
\hline \multirow{6}{*}{$\begin{array}{l}\text { ARS Lisboa e Vale do } \\
\text { Tejo }\end{array}$} & ACES Almada -Seixal & Centro de Saúde do Monte Caparica. \\
\hline & \multicolumn{2}{|l|}{$\begin{array}{l}\text { ACES Arco Ribeirinho } \\
\text { Centro de Saúde da Moita. }\end{array}$} \\
\hline & ACES Médio Tejo & Centro de Saúde de Fátima. \\
\hline & ACES Lezíria & $\begin{array}{l}\text { Centro de Saúde de Salvaterra de Magos; } \\
\text { Centro de Saúde do Cartaxo; } \\
\text { Centro do Saúde de Rio Maior. }\end{array}$ \\
\hline & ACES Estuário Tejo & $\begin{array}{l}\text { Centro de Saúde da Azambuja; } \\
\text { Centro de Saúde de Alenquer; } \\
\text { Centro de Saúde da Arruda dos Vinhos. }\end{array}$ \\
\hline & ACES Oeste Sul & $\begin{array}{l}\text { Centro de Saúde da Lourinhã; } \\
\text { Centro de Saúde Mafra -Ericeira. }\end{array}$ \\
\hline
\end{tabular}

Fonte: Despacho n. ${ }^{\circ} 4324 / 2008$, de 22 de janeiro ${ }^{39}$

Cada centro de saúde terá um dentista, um higienista oral e um assistente para garantir um conjunto diversificado de tratamentos.

ISSN 1982-8829 Tempus, actas de saúde colet, Brasília, 11(4), 25-39, dez, 2017. Epub Ago/2018 
As experiências piloto e as consultas com cheque dentista têm monitoramento e supervisão rigorosos, realizados pelas Administrações Regionais de Saúde (entidades descentralizadas do Ministério da Saúde, responsáveis pela assitência à saúde em cada uma das cinco regiões de Portugal) que visitam regularmente os locais onde decorrem as experiências do sector publico; pela Direção-Geral da Saúde que fiscaliza a atividade realizada nos centros de saúde e nos consultórios privados por médico em cada dia da semana e pela Entidade Reguladora da Saúde que por meio de visitas não programadas avalia a qualidade e garante as condições adequadas ao exercício da prática clínica. Além disso, foi desenvolvida uma base de dados integrados num Sistema de Informação para Saúde Oral (SISO), cujos resultados estão disponível públicamente na área da transparência do Portal SNS ${ }^{11}$ (www.sns.gov.pt) e a partir da qual se elabora um Boletim individual de Saúde Oral que pode ser consultado em qualquer unidade de saúde. A avaliação da experiência tem também em conta a satisfação dos doentes, os tempos de resposta dos consultórios privados e dos Centros de Saúde e ainda a confirmação junto do paciente se o tratamento foi realmente realizado.

\section{CONCLUSÕES}

A criação de um Serviço Nacional de Saúde não teve em conta as necessidades da população no que respeita à saúde oral. Desde meados dos anos 80 a estratégia foi concretizada através de uma parceria com o setor privado por meio de um processo de negociação de contratos com estomatologistas e médicos dentistas que decorre, desde o ano 2000, em todas as Administrações Regionais de Saúde (ARS). Nos anos 90, a saúde oral focou estratégias escolares de prevenção de doenças orais e diagnóstico precoce.

Considerando que a patologia bucal pode estar relacionada com danos físicos e psíquicos, absenteísmo escolar e laboral, gastos em saúde e a não produção de riqueza, em 2005, foi então implementado um Programa Nacional de Promoção da Saúde Oral (PNPSO) com foco nas escolas e jardins-de-infância substituindo o Programa de Promoção da Saúde Oral em Crianças e Adolescentes. Ambos os programas tinham acordo com o setor privado, residindo a princial diferença no modelo de referenciação, monitoramento, qualidade e acesso. No PPSCOCA, a referenciação era limitada e realizada por uma equipe de saúde escolar que encaminhava a criança para um prestador privado convencionado, sem registros ou qualquer monitorização dos trabalhos realizados com pagamento em função do número de crianças e não por intervenção. No caso do PNPSO, a referenciação é realizada pelo médico de familia que atribui um cheque para cada intervenção (pagamento por acto e não por criança) e tem registro obrigatório por parte do parceiro privado de tudo o que fez, sendo frequentemente monitorado e inspecionado pelas Administrações Regionais de Saúde, DireçãoGeral da Saúde e Entidade Reguladora que aplica pesadas coimas.

Com o novo programa depressa se avançou para uma prestação ao longo do ciclo da vida, sendo terminada a contratualização de profissionais alargada a estratégia de cheque-dentista com o setor privado para mais população ao longo de 10 anos. 
Desde 2015 são beneficiários do programa as crianças e jovens dos 3 aos 18 anos, as grávidas seguidas no Serviço Nacional de Saúde, os beneficiários do complemento solidário para idosos e os utentes portadores com o vírus do HIV/AIDS e ainda passou a incluir a intervenção precoce no câncer oral.

No ano 2016, foi iniciado um processo de internalização da prestação de cuidados de saúde oral na atenção primária, mantendo no curto/médio prazo em paralelo a relação com o sector privado, até que no futuro exista capacidade de resposta para todas as necessidades no sector público. Foram iniciadas experiências para avaliar a extensão do projeto ao resto do país. Esta estratégia terá de ser avaliada em comparação com os resultados dos programas cheque-dentista para assim tomar a decisão que melhor sirva aos interesses do país, o que irá ocorrer apenas quando existir uma cobertura em todo o país, o que se estima que venha a ocorrer já no ano 2019.

\section{REFERÊNCIAS}

1. Malta D, Neto O, Silva M, Rocha D, Castro A, Reis A, Akerman M. Política Nacional de Promoção da Saúde (PNPS): Capítulos de uma caminhada ainda em construção. Ciência e Saúde Coletiva. 2016; 21(6):1683-1694.

2. Antunes M. A doença da saúde. SNS: Ineficiência e desperdícios. Lisboa: Quetzal editores; 2000 .

3. Rego G. Gestão empresarial dos serviços públicos. Uma aplicação ao setor da saúde. Porto: Vida Económica; 2011.

4. Barros P. Economia da saúde - conceitos e comportamentos ( $3^{\mathrm{a}}$ edição). Coimbra: Almedina; 2013.

5. Portugal. Constituição da República. Lisboa: Assembleia da República; 1974.

6. Nunes A. A gestão hospitalar empresarial na perspetiva dos gestores hospitalares. Lisboa: Instituto Superior de Ciências Sociais e Políticas (Tese de Mestrado); 2013.

7. Nunes R, Brandão C. Humanização na Saúde. Coimbra: Gráfica de Coimbra; 2007.

8. Nunes R, Rego G. Hospital Fundação Estatal. Porto: Faculdade de Medicina da Universidade do Porto; 2009.

9. Nunes R. Regulação da saúde. 2a Edição. Porto: Vida Económica; 2009.

10. Portugal. Despacho n. ${ }^{o}$ 153/2005, de 5 de janeiro. Diário da República, 2. a série; 153.

11. Portal SNS. Atividade do Programa Nacional de Saúde Oral [Citado 2018 jun 20]. Disponível

ISSN 1982-8829 Tempus, actas de saúde colet, Brasília, 11(4), 25-39, dez, 2017. Epub Ago/2018 
em: https://transparencia.sns.gov.pt/explore/?sort=title\&q=oral/.

12. Patel R. The State of Oral Health in Europe. Better oral health. Report Commissioned by the Platform for Better Oral Health in Europe, 2012.

13. FDI - World Dental Federation. Conduzir o Mundo a uma Otima Saude Oral: Uma refexão sobre o futuro da saúde oral. United States: World Dental Federation; 2016.

14. Fatahzadeh M. Inflammatory bowel disease. Oral Surgery, Oral Medicine, Oral Pathology, Oral Radiology, and Endodontology. 2009;108(5):1-10.

15. Daley T, Armstrong J. Oral manifestations of gastrointestinal diseases. Canadian Journal of Gastroenterology. 2007;21(4):241-4.

16. Korzenik J.Past and current theories of etiology of IBD: toothpaste, worms, and refrigerators. Journal of Clinical Gastroenterology. 2005; 39(4 Suppl):59-65.

17. Yamashita J, Moura-Grec P, Capelari M, Sales-Peres A, Sales-Peres S. Manifestações bucais em pacientes portadores de Diabetes Mellitus: uma revisão sistemática. Revista de Odontologia UNESP. 2013;42(3):211-220.

18. Costa S, Silva A, Macedo A. Conhecimento de de manifestações orais da leucemia e protocolo de atendimento odontológico. Revista de odontologia da universidade Cidade de São Paulo. 2011; 23(1):70-78.

19. Azenha M, Lacerda S, Bim A, Caliento R, Guzman S. Celulite facial de origem odontogênica. Apresentação de 5 casos. Revista Cirurgia Traumatologia Buco-Maxilo-Facial. 2012;12(3):41-48.

20. Duarte H, Sato F, Moraes M. Pericoronarite e infecções das vias aéreas superiores: revisão. Revista Clínica de Pesquisa Odontologic. 2007;3(2):125-132.

21. Fernandes P, Durão S. Tratamento dermato-odontológico para a alopécia areata. Relato de caso clínico. Revista Odontologica UNESP. 2009;38(4):263-66.

22. Pfaller M.Microbiologia Médica. Rio de Janeiro: Elsevier; 2014.

23. ERS - Entidade Reguladora da Saúde. Acesso, concorrência e qualidade no setor convencionado com o SNS. Porto: ERS; 2013.

24. DGS - Direção-Geral da Saúde. Circular Normativa nº1/DSE de 18 de janeiro de 2005. Lisboa: Ministério da Saúde; 2005.

25. Portugal. Despacho n. ${ }^{\circ}$ 4324/2008, de 22 de janeiro. Diário da República, 2. a série; 35. 
26. DGS - Direção-Geral da Saúde. Circular Informativa nº 4, de 27 de fevereiro 2008. Lisboa: Ministério da Saúde; 2008.

27. DGS - Direção-Geral da Saúde. Circular normativa n²/DSPPS/DCVAE de 9 de janeiro. Lisboa: Ministério da Saúde; 2009.

28. Portugal. Portaria n. ${ }^{\circ}$ 301/2009, de 24 de março. Diário da República, 2. a série; 58.

29. DGS - Direção-Geral da Saúde. Circular Normativa nº8, de 20 de abril de 2010. Lisboa: Ministério da Saúde; 2010a

30. Souza L, Pereira Pinto L, Medeiros A, Araújo Júnior R, Mesquita O. Manifestações orais em pacientes com AIDS em uma população brasileira. Revista Brasileira de Odontologia. 2000;14(1):79-85.

31. Gillespie G, Marinho R. (1993). Oral manifestations of HIV infection: a Panamericana Perspective. Journal of Oral Pathologie. 1993;22(1):2-7.

32. Portugal. Despacho n. ${ }^{\circ}$ 16159/2010, de 24 de março. Diário da República, 2. ${ }^{a}$ série; 208.

33. DGS - Direção-Geral da Saúde. Norma da DGS N.002/2010. Lisboa: Ministério da Saúde; $2010 b$.

34. Portugal. Decreto Regulamentar n. ${ }^{\circ} 14 / 2012$, , de 26 de janeiro. Diário da República, 2. ${ }^{a}$ série; 19.

35. Direção-Geral da Saúde. Circular Normativa nº13. Lisboa: Ministério da Saúde; 2013.

36. Portugal. Despacho n. ${ }^{\circ}$ 686/2014, de 6 de janeiro. Diário da República, 2. a série; 10.

37. Portugal. Despacho n. ${ }^{\mathrm{o}}$ 12889/2015, de 13 de novembro. Diário da República, 2. ${ }^{\mathrm{a}}$ série; 233.

38. Portugal. Programa do XXI Governo Constitucional: saúde. Lisboa: Governo de Portugal; 2015.

39. Portugal. Despacho n. ${ }^{\circ}$ 8591-B/2016, de 1 de julho. Diário da República, 2. a série; 125.

Artigo apresentado em 21/10/17

Artigo aprovado em 20/03/18 Artigo publicado no sistema em 31/08/18 